\title{
ENSAIO SOBRE A FRAGILIDADE AMBIENTAL DA SUB- BACIA DO CÓRREGO DA OLGA - PRESIDENTE PRUDENTE- SP
}

\section{Bruno Sandrin Nascimento'}

\author{
José Mariano Caccia Gouveia ${ }^{2}$
}

RESUMO: Partindo da consideração de que os recursos naturais são utilizados historicamente pelo homem como potencial produtivo e de uso para a manutenção do sistema econômico a fim de suprir a demanda de determinados setores, hoje, tem-se um consenso nas comunidades deste uso dos recursos naturais considerarem a conservação e preservação nos aspectos qualitativos e quantitativos. Assim, tem-se uma necessidade de conhecimento da potencialidade e da fragilidade, o limite máximo e mínimo o qual um determinado ambiente suporta e interferência antrópica, baseando-se, portanto no Planejamento Ambiental, que atualmente vem sendo adotado pelo poder público e privado, reestruturado pelo Geoprocessamento e Sensoriamento Remoto, a fim de diminuir os custos e aprimorar os resultados finais, contribuindo à eficácia do projeto e diminuindo o tempo com que os procedimentos são realizados. $O$ Planejamento Ambiental adota métodos e Técnicas a serem abordada, tal como a análise da fragilidade dos ambientes, a fim de interpretar a fragmentação das áreas as quais possuem maior ou menor fragilidade, sendo esta ocupada pelo homem ou não.

PALAVRAS-CHAVE: Fragilidade. Planejamento. Geoprocessamento.

\footnotetext{
1 Graduando em Geografia na FCT/UNESP, Presidente Prudente, SP (nascimentobruno.unesp@gmail.com)

2 Professor Assistente Dr. FCT/UNESP, Presidente Prudente, SP (jmarianocaccia@gmail.com)
} 


\section{ASSAY ON ENVIRONMENTAL FRAGILITY IN SUB-BASIN OLGA STREAM - PRESIDENT PRUDENTE SP}

RESUME: Considering that the natural resources are used by man as productive potential and used to economic maintenance system that aims to supply the demanding of determined sectors, today, there is consensus in the communities about the use of these natural resourses considering the conservation and preservation at quantity and quality aspects. Therefore there is necessity of the knowledge about the fragility and potenciality, the maximun and minimun limit that a determined environment support the anthropoid interferences based on the Environment Planning, that has been adopted by Public and Private Law, that has been reestructured by Geoprocessing and Remote Censorship, with the objective of diminishing costs and improve the final results, contributing to the efficience of the project and in short time as the accomplished procedures. The Ambiental Planning gets methods and techniques to be approached, as well the analyze of the environment fragility, it aims the comprehension of the fragmentation of the areas that get higher and lower fragility, being or not occupied by man.

KEYWORDS: Fragility. Planning. Geoprocessing.

\section{ENSAYO SOBRE LA FRAGILIDAD AMBIENTAL EN LO SUBCUENCA DEL ARROYO OLGA - PRESIDENTE PRUDENTE $S P$}

RESUMEN: Empezando del presupuesto de que los recursos naturales se han utilizado históricamente por el hombre como un potencial productivo y de manutención del sistema económico con la finalidad de atender la demanda de ciertos sectores, hoy en día, existe un consenso en las comunidades de que este uso de los recursos naturales debe tener en cuenta la conservación y preservación de los aspectos cualitativos y cuantitativos. Por lo tanto, hay una necesidad de conocimiento del potencial y fragilidad, los valores máximos y mínimos que dan un apoyo de entorno y la interferencia humana, basadas, por ello, de Planificación Ambiental, que actualmente está siendo adoptada por el poder público y privado, reestructurado el SIG y la teledetección con el objetivo de reducir costos y mejorar la línea de fondo, lo que contribuye a la efectividad del diseño y reduce el tiempo que se llevan a cabo los procedimientos. El Planificación Ambiental adopta métodos y técnicas que deben abordarse, tales como el análisis de la fragilidad de los ambientes, con el propósito de interpretar la fragmentación de las zonas más o menos frágiles, ocupadas o no por el hombre.

PALAVRAS-CHAVE: Fragilidad. Planificación. Geoprocessamiento. 


\section{ANAP $B_{r a s i}$ \\ ISSN 1904-3240 \\ V. 8, n. 11}

\section{REVISTA}

\section{Introdução}

Partindo de um consenso científico atual tanto nas ciências geográficas como tantas outras objetivadas aos estudos sociais, físicos e ambientais. A abordagem holística, sistêmica ou multifatorial tem ganhado espaço em detrimento de uma representação, seja em mapas, gráficos ou técnicas de modelagem, o inter-relacionamento de fatores, elementos ou ditas "camadas" e suas respectivas funcionalidades, voltadas à compreensão da realidade expressa nestes "modelos" representacionais.

Contudo, a análise e/ou estudo integrado da paisagem baseado em princípios e pressupostos sistêmicos, a qual interpreta que cada elemento/componente contém uma parcela de participação no contexto totalitário, considerando a sua funcionalidade visto que, este interrelacionamento destes componentes, circunscreve um sistema de relações, que operando conjuntamente através dos Fluxos de Energia e Matéria constrói um padrão dinâmico de formas e características, regionalizadas ou locais, analisando os elementos aninhados hierarquicamente. (Chorley e Kennedy, 1971; Haigh, 1985 apud Christofoletti, 1999).

Esses sistemas baseados em fluxos e transferências de energia e matéria, comandado entre o antagonismo das características históricas e atuais tanto da atmosfera como também do interior da crosta terrestre, consubstanciado pela participação da água em qualquer estado físico repercute nos caracteres fisionômicos, paisagísticos passados e atuais predominantemente associados à inserção do homem, havendo uma variância da intensidade das trocas de energia e matéria entre as partes (Ross, 1995: pág. 71). Associando, portanto o contexto a uma necessidade analítica multifatorial e supostamente dinâmica, visto que segundo Martinelli (1994), tem-se a necessidade de atualizações dos dados e mapas quanto à evolução dos elementos em função do fator tempo e não somente no espaço, porém, 


\section{ANAP $B_{\text {rasil }}$ \\ ISSN 1904-3240 \\ V. 8, n. 11}

\section{REVISTA}

trazendo a busca da representação ambiental através do co-relacionamento dos elementos.

$\mathrm{Na}$ mesma perspectiva, num conteúdo mesmo que crítico, Martinelli (pág. 68: 1994) contorna o propósito da representação da cartografia sintética ou multifatorial não podendo mais analisar os produtos intermediários, que não seja com finalidades de caracterização, não tecendo a visão estática ou unilateral, mas sim o produto final do inter-relacionamento dos produtos temáticos analíticos (precedente ao sintético), devendo, portanto, destacar áreas com atributos semelhantes ou iguais dentro da classificação em questão, não se tratando de análises setorizadas da sociedade e da natureza (Ross, 1995).

Dentre estes preceitos adotados, considerando as contribuições dos autores citados, trata-se de dada necessidade referente ao mapeamento, estudo ou análise inter-relacionada das partes do complexo paisagístico e ambiental, que numa proposta de bases teórico-metodológica integra as partes desagregadas da paisagem através da elaboração de cartas de Fragilidade Ambiental, proposto por Ross (1994) num conteúdo descritivo das condições ambientais a partir da integração de dados geográficos e Sanchéz (1991) que mesmo que numa tipologia analítica estruturada na agroecologia busca também a sistematização da análise ambiental hierarquizada, visto que ambos consubstanciam o planejamento, seja pelo primeiro autor ambiental como pelo segundo autor o planejamento ecológico-paisagístico em áreas rurais.

\section{Objetivos}

Objetiva-se neste trabalho, um ensaio da análitico da Fragilidade Ambiental de uma sub-bacia hidrográfica, apresentando, dentro da metodologia, o contexto do sistema ambiental através dos resultados adquiridos, tendo em vista uma abordagem holística da paisagem a qual a unidade em questão se insere. Contudo busca uma associação dinâmica e 


\section{ANAP $B_{\text {rasil }}$}

ISSN 1904-3240

V. 8, n. 11

classificatória das partes que a compõem através de métodos e ferramentas de geoprocessamento e sensoriamento remoto para a realização dos produtos intermediários ou cartas temáticas, tomando a compartimentação das unidades geomorfológicas, antrópicas (uso da terra e cobertura vegetal natural remanescente) e pedológicas, por fim associadas e possibilitando a estruturação da carta de Fragilidade Ambiental, o qual consiste em um produto passível de análises e pressupostos direcionais ao planejamento e futuro uso da terra na área.

\section{Materiais}

Dentre os dados e materiais utilizados para a realização do trabalho foram utilizadas imagens de satélite Cbers-4 do sensor MUX com a órbita 160 e ponto 122 datada em 19 de janeiro de 2015 (19/01/2015) disponibilizadas no catálogo de imagens de satélite do Instituto Nacional de Pesquisas Espaciais (INPE) sendo necessárias para a identificação das feições utilizadas para a carta de uso da terra e cobertura vegetal.

$\mathrm{Na}$ descrição semidetalhada das feições do relevo para a Carta Geomorfológica foram utilizados produtos do programa Shuttle Radar Topography Mission (SRTM) com resolução de 30 metros, disponibilizados para download através do portal TOPODATA oferecidos gratuitamente pelo INPE adquirindo para este trabalho a folha 22S525. Para o tratamento e manipulação dos arquivos tanto as imagens (Cbers-4 e SRTM) adotou-se o Softwares Quantum GIS Pisa 2.10-1 que através do Painel de Processamento fora utilizado o Software SagaGIS para a geração de dados secundários como - Sombreado necessários à interpretação das feições do relevo e extração da Declividade e Cotas Altimétricas do SRTM.

Para levantamento de campo e correção geométrica da imagem de satélite e a confirmação do uso da terra, utilizou-se um receptor de GPS de navegação Garmim Etrex 30. Quanto ao mapeamento semi-detalhado dos 


\section{ANAP $B_{r a s i}$ \\ ISSN 1904-3240 \\ V. 8, n. 11}

\section{REVISTA}

solos, considerando a contribuição de Carvalho (1997), os mapas resultantes foram digitalizados e vetorizados em ambiente SIG (Sistemas de Informações Geográficas) também no Software Quantum GIS.

Esta base de dados e materiais adotados para a elaboração do trabalho contribuiu à realização dos produtos intermediários para a contextualização das análises no tocante central abordado.

\section{Método}

A metodologia adotada é baseada na proposta empírica da Análise da Fragilidade de Ambientes Naturais e Antropizados proposta por Ross (1994) o qual adota uma base teórico-metodológica fundamentada em Tricart (1977). Sendo assim, o método adotado neste trabalho foi aplicado na sub-bacia do Córrego da Olga, situado no Município de Presidente Prudente - SP, sub as coordenadas UTM WGS 1984, 458143.95895W e 7546847.7957S zona 22 Sul.

A Sub-bacia hidrográfica como unidade geográfica e ambiental adotada, contorna as bases para o planejamento e gestão dos recursos naturais, visto que dentro da unidade há a presença de uma transição entre divergências quanto ao uso do solo, permeando como área de transição entre o ambiente rural e urbano, associando por fim a inserção da sub-bacia do córrego da Olga dentro do contexto do manancial superficial do Rio Santo Anastácio.

O trabalho realizado é substanciado pelo método proposto por Ross (1994) para análises da fragilidade de ambientes naturais como também para ambientes os quais se encontram sob muito forte ou muito fraca influência do homem. Dentro da proposta metodológica cabe salientar o conteúdo analítico de outros autores, os quais consideram tanto a paisagem como unidade analítico-geográfica em função de maior ou menor grau de interferência antrópica, ou mesmo, ambiente considerados "frágeis", determinando a pertinência das contribuições de Sánchez, (1991). Dedicado às análises 


\section{ANAP

integradas dos elementos e componentes do estrato geográfico em detrimento de um ordenamento ou planejamento dos tipos de usos e interferências antrópicas no meio rural.

Deste modo, ambos determinam a importância de um zoneamento das partes que compõem o contexto global da paisagem, abordando uma etapa analítica dos recursos e potencialidades da área para que se tenha ao fim uma fase de síntese, visando através do contexto de cada elemento a composição da paisagem em um modelo que serve principalmente à atividades de planejamento, podendo em diferentes segmentos e/ou metodologias adotadas a aplicação que melhor se encaixe ao objetivo final, sendo necessário um sistema de procedimentos teórico-metodológico que de coerência frente classificação aos produtos e análises intermediárias de modo que não se tenha uma aproximação máxima da realidade, visto que este serve como proposta à planos de ação, tanto para o setor privado como público.

A base analítica deste trabalho discutida por Ross (1994), o qual trabalha a questão de interpretação das escalas de fragilidade dos ambientes em uma determinação de muito fraca a muito forte, inserindo nas pesquisas e determinações da dinâmica de Tricart (1977) em função do equilíbrio entre os componentes a partir de uma dinâmica estável, instável ou intergrade, sendo os primeiros classificados a partir do equilíbrio dinâmico relativamente pleno, poupadas das ações do homem as quais, sua dinâmica se encontra dentro de características naturais, os segundos em função da alteração antrópica ou interferências que quebrem este equilíbrio, através de mudanças significantes, seja pelo desmatamento ou práticas econômicas intensas.

A perspectiva adotada do autor que segue um princípio de complementaridade das propostas de Tricart (1977) adaptando a proposta inicial para o contexto do planejamento, interpretando as Unidades Ecodinâmicas Instáveis ou de Instabilidade Emergente em graus de fragilidade Muito Fraca a Muito Forte, sendo aqui o caso, visto que a interferência 


\section{ANAP $B_{\text {rasil }}$}

ISSN 1904-3240

V. 8, n. 11

antrópica estabeleceu-se hoje e em períodos históricos no processo de ocupação da região.

Seguindo esta linha de interferência a qual considera ou não as ações do homem, o qual, não discrimina a probabilidade de eventualidades naturais que aceleram os processos (re) modeladores do relevo e paisagem preponderando os processos geomorfogenéticos aos pedogenéticos, cabe aqui, comentar as unidades morfo-fito-pedológicas (Sánchez, 1991: pág. 69) aplicadas ao zoneamento de paisagens no planejamento rural, interpretando como a dinâmica natural herdada do período quaternário que resulta na dinâmica e materialização dos processos na espacialização e funcionalidade dos componentes das paisagens atuais, materializados na superfície morfopedológica, integralizando os processos pedogenéticos e morfogenéticos que resultam de maior ou menor estabilidade dinâmica da paisagem (Tricart, 1977).

No tocante interpretativo, de inter-relação entre os elementos bióticos, geomorfológicos e pedológicos, cabe a inserção do homem como um agente acelerador das condições geomorfogenéticas, visto que este interfere na dinâmica das paisagens predominantemente a partir da inserção de tecnologias e retirada da cobertura vegetal, assim sendo o caso da área estudada, tendo a retirada do estrato arbóreo da vegetação natural (Mata Estacional Semidecidual) para o desenvolvimento de atividades de pecuária, determinando a simplificação biológica e compondo a ausência de uma camada protetora do solo e fornecedora de matéria orgânica à níveis de estado natural preexistente, resultando em uma reestruturação biológica e funcionalidades conservacionistas, acionando os processos morfodinâmicos em função dinâmica climática local (Sánchez, 1991: pág. 19).

Não se atrelando somente às questões de degradação da composição biótica das paisagens, considerando a causa e efeito num sentido decadente do solo (Primavesi, 1998 apud Sánchez, 1991), o estado conteúdo sistêmico de inter-relação e interdependência dos elementos da paisagem baseado na 


\section{ANAP Brasil $_{\text {ra }}$ \\ ISSN 1904-3240 \\ V. 8, n. 11}

\section{REVISTA}

perda de material das porções de maior altimetria não "somente" compõem a problemas do solo ou a degradação biótica regional, interferindo também na deposição de sedimentos e materiais nas porções mais baixas repercutindo nos aspectos qualitativos e quantitativos dos recursos hídricos locais.

Seguindo as propostas de diferentes autores e sistemas de análise, a base para caracterização da fragilidade ambiental da área estudada, seguiu-se a conceituação do processo analítico, onde a necessidade de caracterização do meio físico se faz necessária, como também, a base para elaboração do produto final a partir dos produtos intermediários.

A representação geomorfológica dentro da proposta, seguindo a proposição de Ross (2000), considerando a escala, sistematizou-se a análise e identificação conteúdo geomorfológico a partir do 5ำ (quinto) táxon, referindo-se as partes das formas do relevo a partir da setorização das vertentes, identificando na área setores de vertentes classificadas em Vertentes Côncavas (Vcc), Convexas (Vc), Retilíneas (Vr), Topos Convexos (Tc) e Planícies Fluviais (Apf).

Para a aplicação da classificação seguindo as contribuições de Colangelo (1995) considerando os mecanismos de compensação e balanço de energia e troca de matéria ocorrente nos setores de vertente, foram determinadas as classificações de Ross (1994) conforme maior ou menos participação do produto final por parte destes setores, categorizados de Muito Fraco-1 a Muito Forte - 5, descritos na tabela 1.

Considerando os setores de Vertentes Convexas identificadas, as classificações que variam de muito fraco a muito forte, baseia-se na nas proposições de Colangelo (1995) de que os setores convexos da alta vertente Tc e Vc são caracterizados por áreas de maior permeabilidade o qual, há o predomínio das porções mais arenosas do solo, visto que apesar de o segundo apresentar maior declividade e tendo o aumento do escoamento superficial, ainda apresenta maior resistência à erosão e carregamento das partículas de solo frente às vertentes côncavas e retilíneas, as quais apresentam maior 


\section{ANAP

declividade e propiciam o início dos processos erosivos, visto que os processos erosivos estão intimamente ligados à hidrodinâmica superficial e subsuperficial, carreando os materiais de solo para as porções mais baixas das unidades.

\begin{tabular}{|l|l|}
\hline Feição & Classificação (Fragilidade) \\
\hline Topos de Convexos (Tc) & 1 - Muito Fraca \\
\hline Vertentes Convexas $(\mathrm{Vc})$ & 2 - Fraca \\
\hline Vertentes Côncavas(Vcc) & 3 - Média \\
\hline Vertentes Retilíneas (Vr) & 4 - Forte \\
\hline Planícies Fluviais (Apf) & 5 - Muito Forte \\
\hline
\end{tabular}

(Tabela 1) Adaptado de Ross (2000)
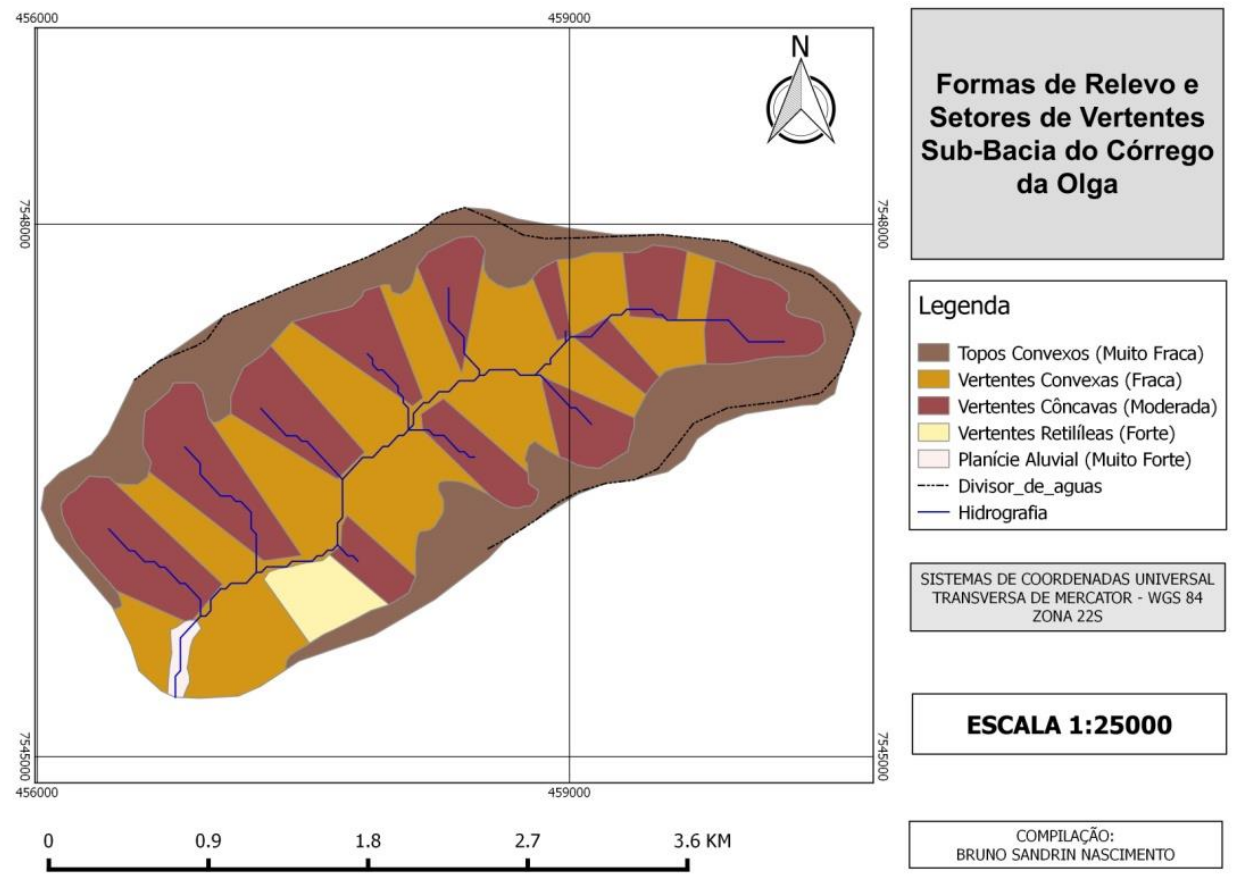

(Figura 1)

Sendo assim, a identificação das formas dentro da área total teve significativa ocorrência dos setores de topos e vertentes convexas, onde somados ocupam $63 \%$ da área total, fator que descreve a capacidade de infiltração da água nos perfis superficiais do solo, apresentando $33 \%$ de 


\section{ANAP

Vertentes Côncavas e 1\% de Planícies Aluviais, não apresentando índices muito altos de fragilidade, considerando aqui o conteúdo analítico setorizado.

\begin{tabular}{|ccccc|}
\hline & & & Vertentes \\
\hline & Topos Convexos & Côncavas & Vertentes & Convexas \\
Planícies Aluviais & $28 \%$ & $33 \%$ & Retilíneas & \\
$1 \%$ & & & $3 \%$ & \\
\hline & & & & \\
\hline
\end{tabular}

(Gráfico 1)

A declividade no contexto do estudo traz uma expressão em porcentagem, classificada a partir da proposição de Ross (1994), visto que para a escala em questão, a declividade traz a finalidade de expressão do ângulo de inclinação do setor identificado, visto que este consiste identificação de maior ou menor resistência das formas de relevo ao escoamento superficial, tendo em maiores declividades um fomento da velocidade do escoamento em função da força da gravidade e/ou maior infiltração da água em função de menores declividades, sendo assim, a declividade no contexto da fragilidade está correlacionada à interpretação morfométrica do relevo, associando às condições morfológicas e a inclinação das feições identificadas em porcentagem, sendo assim a classificação utilizada da declividade estão expressas na tabela 2 :

\begin{tabular}{|l|l|}
\hline Declividade & Classificação (Fragilidade) \\
\hline Muito Fraca -1 & Até $6 \%$ \\
\hline Fraca -2 & De 6 a $12 \%$ \\
\hline Média -3 & De 12 a $20 \%$ \\
\hline Forte -4 & De 20 a $30 \%$ \\
\hline Muito Forte -5 & $>30 \%$ \\
\hline
\end{tabular}

Tabela 2 - Adaptado de Ross (1994) 


\section{ANAP \\ Brasil \\ ISSN 1904-3240 \\ V. 8, n. 11}

\section{REVISTA C IENTÍFICA}
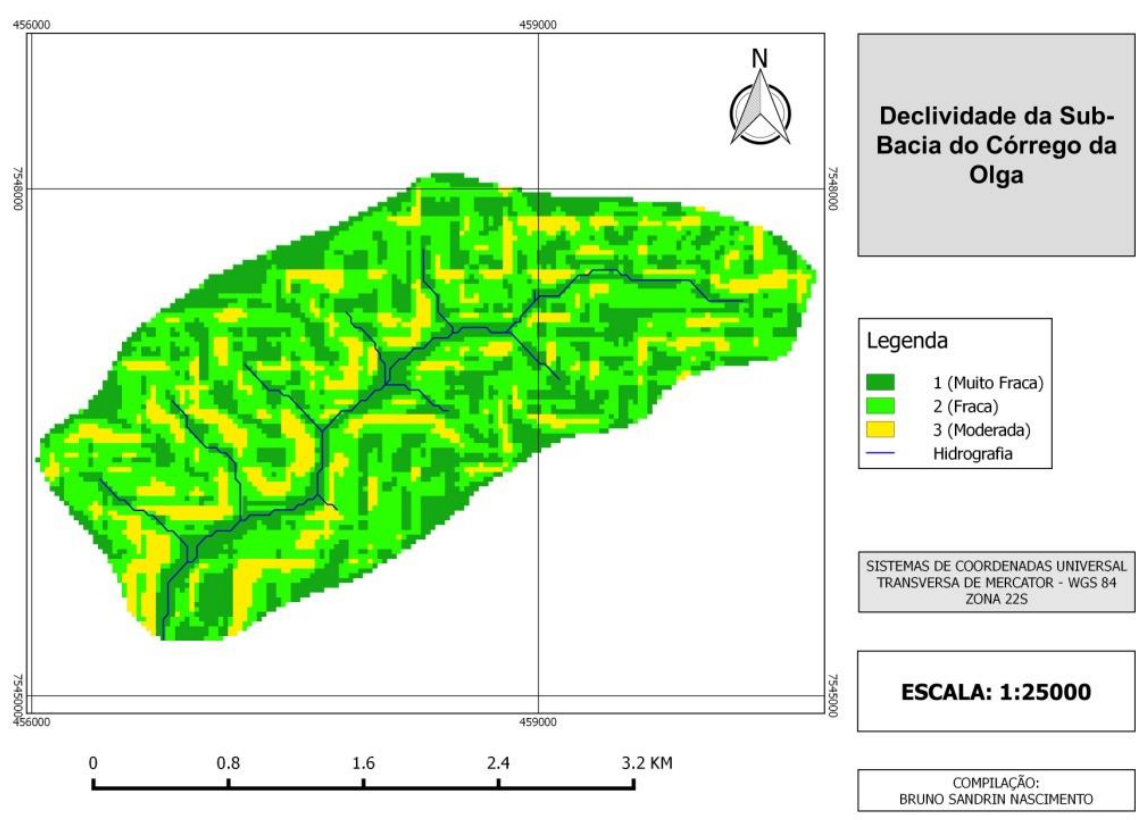

(Figura 2)

A declividade não expressou altos índices de participação na fragilidade ambiental dentro da área, não expressando, no mapa porcentagens de declive superiores a $21 \%$, ou seja, tendo a expressividade de $1 \%$ apenas no gráfico com a expressão Forte.

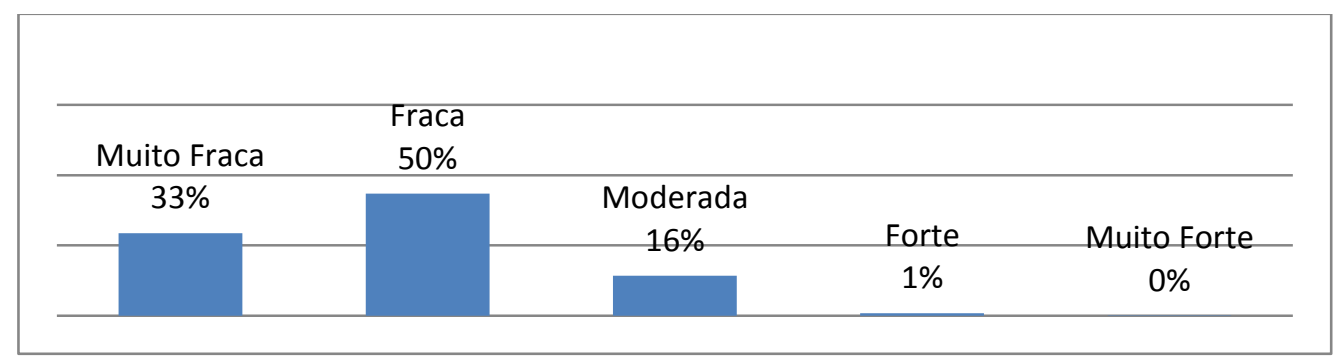

(Gráfico 2)

Deste modo, tendo a área, um caractere plano, visto que a declividade não apresenta altas porcentagens, pode-se dizer que a área apresenta relativa característica dinâmica de infiltração, visto que apresenta considerada característica de convexidade em função das feições geomorfológicas e declividades que não ultrapassam índices muito altos. 


\section{ANAP $B_{\text {rasil }}$}

ISSN 1904-3240

V. 8, n. 11

Considerando as classes de solo identificadas na área a partir do trabalho de Carvalho (1997), representando um levantamento semidetalhado, tem-se a alta distribuição dentro da área dos solos Pve7 e Pea7 predominantemente.

A tabela abaixo descreve as classes de solo encontradas na área e as respectivas características em função da classificação proposta por Ross (1994) e sua área em porcentagem frente à área total.

\begin{tabular}{|c|c|c|}
\hline Classificação & Solos & Área em \% \\
\hline 4 & $\begin{array}{c}\text { PEa7 (Associação Podzólico } \\
\text { vermelho Escuro Abrúptico Álico } \\
\text { Epidistrófico, textura média+Solos } \\
\text { litólicos textura média) }\end{array}$ & 30 \\
\hline 5 & $\begin{array}{c}\text { HGPa2 (associação de solos GLEl } \\
\text { pouco húmico } \\
\text { Álico/Distrófico/Eutrófico com textura } \\
\text { arenosa/média dependendo da } \\
\text { localização }\end{array}$ & \\
\hline 4 & $\begin{array}{c}\text { PEa4 (Podzólico Vermelho Escuro } \\
\text { Álico Tb A, moderado, textura } \\
\text { arenosa/média. }\end{array}$ & \\
\hline 4 & $\begin{array}{c}\text { Ae3 (Solos Aluviais Álicos } \\
\text { Epieutróficos com textura média; } \\
\text { Solos Aluviais Distróficos com } \\
\text { textura média em função da } \\
\text { localização Arenosa; Glei pouco } \\
\text { húmico distrófico e eutrófico } \\
\text { dependendo Ada área com textura } \\
\text { arenosa e média) }\end{array}$ & \\
\hline 5 & $\begin{array}{c}\text { PVe7 (Associação de Podzólico } \\
\text { Vermelho-Amarelo Abruptico A } \\
\text { moderado, textura }\end{array}$ & \\
\hline & arenosa/média+Solos litólicos com \\
& textura arenosa) & \\
\hline
\end{tabular}

(Tabela 3 Adaptado de Carvalho, 1995)

Dentro da caracterização da área pode-se notar a forte presença de solos com uma classificação de forte a muito forte na dinâmica ambiental, considerando que os solos têm forte presença na caracterização da fragilidade, visto que possuem fortes características em função da textura e profundidade do perfil, determinado por solos litólicos e associação de solos podzólicos com textura arenosa, fortes condicionantes à evolução dos processos erosivos, 


\section{ANAP $B_{\text {rasil }}$ \\ ISSN 1904-3240 \\ V. 8, n. 11}

considerando a alta permeabilidade, estes associados à usos irregulares e inconsistentes frente à conservação do equilíbrio de forças na vertente podem evoluir à estágios mais evoluídos de erosão como o afloramento do aquífero no surgimento de voçorocas.
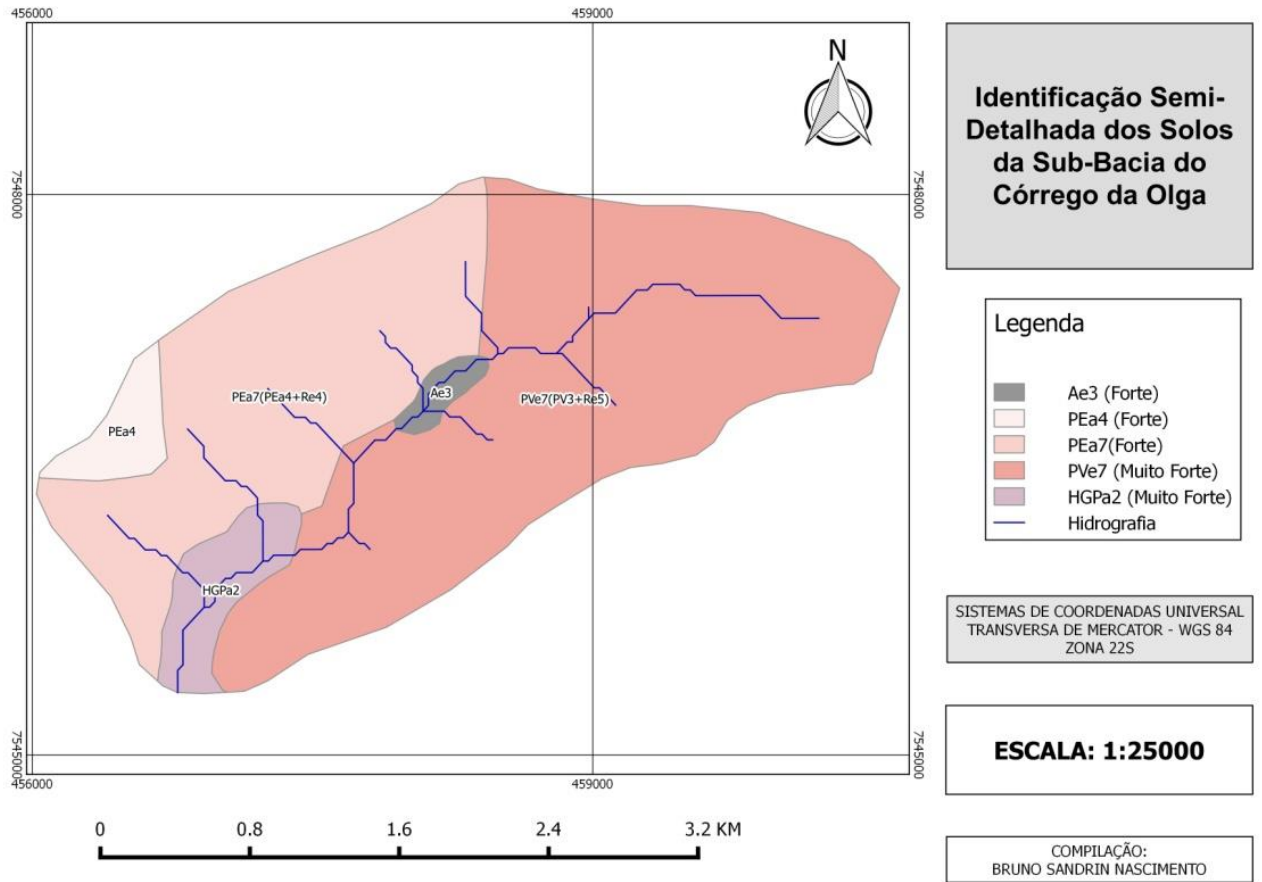

(Figura 3)

Após a caracterização dos elementos do meio-físico da área de estudos, cabe ao procedimento de análise como também a classificação das partes envolvidas frente à inserção do componente antrópico e cobertura vegetal, elementos essenciais ao procedimento, visto que a cobertura vegetal tem papel fundamental às condições ambientais de equilíbrio, porém vulneráveis e essencialmente impactadas pelas ações humanas a partir da inserção das tecnologias de produção ou apropriação dos ambientes.

Sendo assim identificadas na área, três tipologias diferentes de uso da terra e uma de cobertura vegetal, as quais variam desde cobertura arbórea natural remanescente às áreas impermeabilizadas em função da expansão urbana. Visto que a classe identificada como pastagens ocupa $90 \%$ da área 


\section{ANAP

total, considerando-a apesar de não conservar a dinâmica natural, um agente de proteção do solo dada a formação de um escudo superficial de proteção contra o efeito splash, porém desconsiderando biodiversidade regional através da simplificação biológica, que apesar das áreas de pastagem contribuírem à conservação granulométrica das porções superficiais do solo, não contribuem à formação e desenvolvimento dos horizontes orgânicos do solo. Sendo assim, a tabela 4 descreve a classificação das classes de uso da terra e da cobertura vegetal encontrada dentro da área.

\begin{tabular}{|c|c|c|}
\hline Classificação & Tipologia & Área em \% \\
\hline 1 & Cobertura Arbórea & 4 \\
\hline 5 & Solo Exposto / Pastagem Degradada & 3 \\
\hline 3 & Pastagens & 90 \\
\hline 4 & Asfalto / Construções & 3 \\
\hline
\end{tabular}

(Tabela 4)

As áreas e tipologias apresentadas são dispostas na figura 4 outras duas classes identificadas são asfalto e construções, constituindo áreas impermeabilizadas, compondo classificação 4 , e a classe de solos expostos, a qual engloba pastagens degradadas que não contribuem ás pastagens de gramíneas com plano vigor, visto que as primeiras em função do baixo espaçamento e maior irregularidade frente á sua distribuição, consolidam-se entre solo exposto, classificadas juntamente às áreas onde o solo exposto fora encontrado dentro de uma classe só. 


\section{ANAP \\ Brasil \\ ISSN 1904-3240 \\ V. 8, n. 11}

\section{REVISTA C I EN TÍFICA 2015}

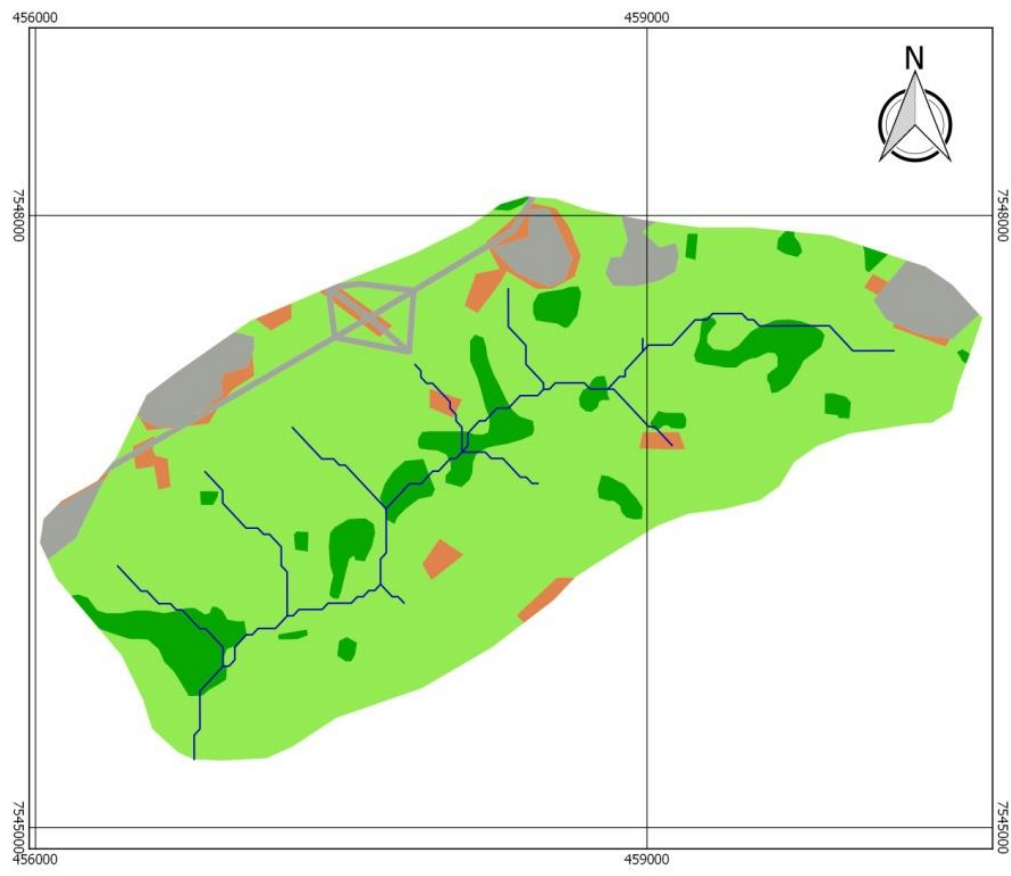

0

0.8

1.6

2.4

$3.2 \mathrm{KM}$

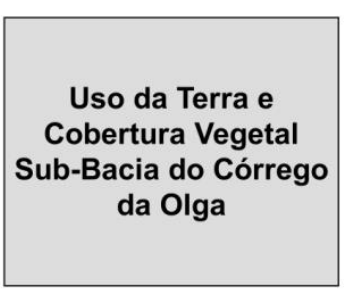

\begin{tabular}{|l|}
\hline Legenda \\
Pastagem (Moderada) \\
Áreas Impermeabilizadas (Forte) \\
Cobertura Arbórea (Fraca) \\
Solo Exposto (Muito Forte) \\
— Hidrografia \\
\hline
\end{tabular}

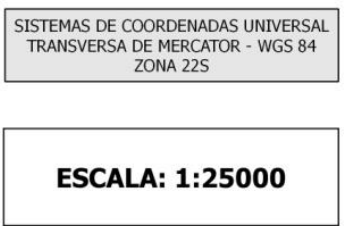

COMPILACÃO:
BRUNO SANDRIN NASCIMENTO

(Figura 4)

Ao fim do processo analítico e cartográfico para o mapeamento e identificação das características do meio físico e o comportamento antrópico na área em função do uso e ocupação do solo, temos aqui a apresentação dos procedimentos realizados em ambiente SIG, a partir da combinação das "camadas" que caracterizam a discussão, sendo assim, esta combinação fora realizada no Software Quantum Gis 2.10-1 utilizando a ferramenta Calculadora Raster para a combinação das camadas a partir da formula:

$\mathrm{Fa}=(\mathrm{R}+\mathrm{D}+\mathrm{U}+\mathrm{S}) / 4$

Fa: Fragilidade Ambiental

R: Relevo

D: Declividade

U: Uso da Terra e Cobertura Vegetal

S: Solos 


\section{ANAP

Deste modo, seguindo a proposta de Ross, houve dados resultantes a partir desta combinação, refere-se a fragilidade ambiental, considerando os pesos em função de graus de fragilidade de muito fraco a muito forte, visto que a vegetação ocupa a porção do grau de proteção, esta ocupa as porções mais fracas da fragilidade. Assim, reconsiderando a análise do sistema considerando a afirmação de sistema conforme Haigh (1985) apud Christofoletti (1999) o qual determina um sistema a partir da sua totalidade, visto que independente do conteúdo analítico, seja para potencialidade agrícola ou mapas de aptidão como fragilidade ou vulnerabilidade estes procedimentos os quais admitem o conteúdo dinâmico da paisagem são necessários, procedentes ao processo analítico das componentes isoladas da paisagem.

\section{Resultados e Discussão}

Considerando os dados resultantes da pesquisa, apresentados no gráfico 3 e figura 5, a área encontra-se predominantemente com características de fragilidade Forte dentro da escala de análise de Ross (1994).

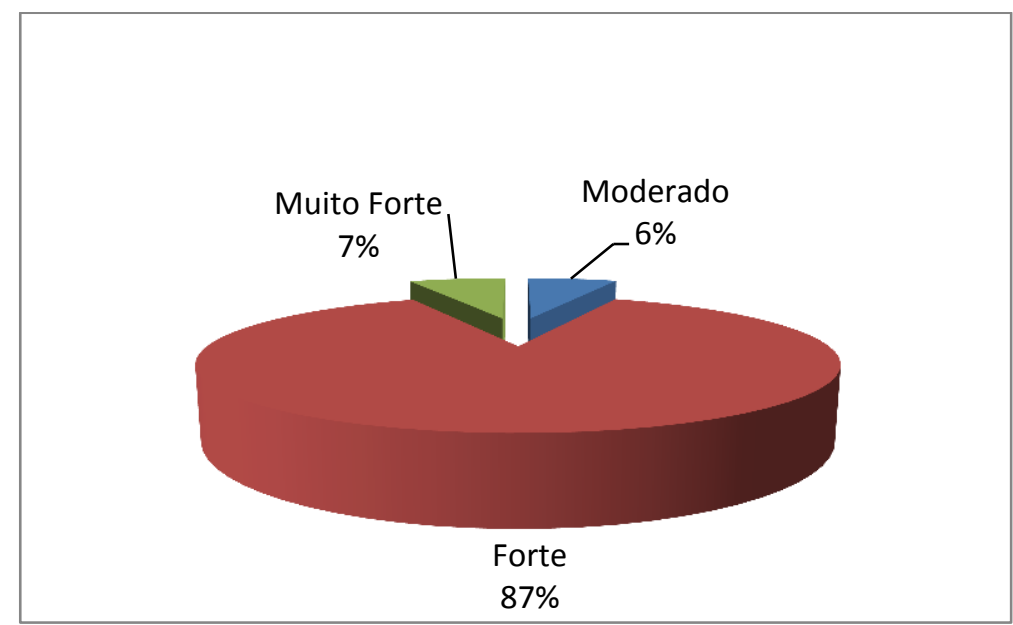

(gráfico 3)

Sendo assim, pode-se dizer que a área encontra-se sob forte influência antrópica, considerando que se encontra nas intersecções das futuras 


\section{ANAP

influências que a expansão urbana circunscreve na área como também a utilização dos recursos naturais da área em função das atividades agrícolas que não consideram técnicas conservacionistas ou mesmo uso do solo a partir de culturas menos agressivas à fertilidade do solo ou sistemas de controle de erosão.

Assim, pode-se notar a interferência das áreas de cobertura vegetal arbórea remanescente nas áreas, diminuindo o grau de conservação da dinâmica natural, amenizando os índices de forte para moderado, quebrando o predomínio homogeneizado da classe Forte, assim representados na figura abaixo.

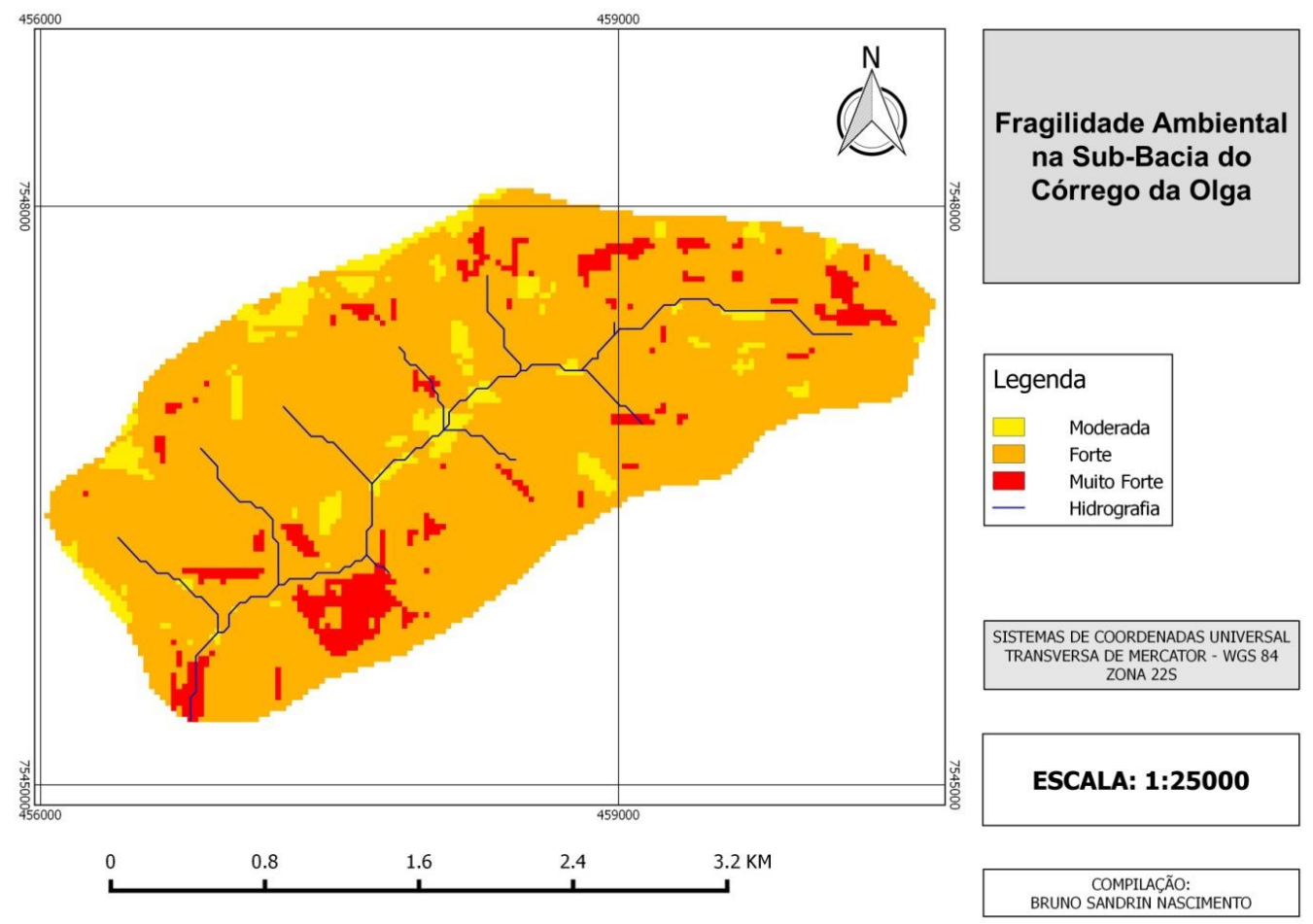

(Figura 5)

Considerando os outros elementos abordados nos procedimentos analítico-cartográficos, temos a presença de fragilidade em índices muito forte nas áreas de Planícies Aluviais e o domínio das Vertentes Côncavas, como 


\section{ANAP $B_{\text {rasil }}$ \\ ISSN 1904-3240 \\ V. 8, n. 11}

também a participação das áreas de construção e asfalto em detrimento da classe considerada Forte.

Os fins analíticos pode-se dizer que a área se encontra sob um domínio de fragilidade predominantemente forte, como apresentado pelo gráfico e pelo mapa, sendo assim classificada como área de Instabilidade Emergente, Moderada a Muito Forte, dispondo apenas das três classes de maior instabilidade e preocupações frente às questões de planejamento e gestão dos recursos naturais, visto que as ações antrópicas alteraram ao longo do tempo a partir das atividades agrícolas e hoje, em função da expansão urbana na área, aqui, não se abstendo as questões de tipologia de uso ou parcelamento do solo urbano, apresentando um sistema de detecção de áreas fortemente instáveis, cuja característica a partir do modelo, pode-se interpretar condições negativas em função dos resultados obtidos.

\section{Conclusão}

Dentro do modelo gerado, foi possível a interpretação de dois aspectos principais, o primeiro, sendo, o comportamento de todas as partes em função dos resultados finais através da síntese dos elementos e componentes ambientais e seus comportamentos inter-relacionados aos outros elementos, 0 qual compôs o produto final, sendo assim, considerando os aspectos analíticos e o método adotado a partir de diferentes interesses ao produto final, porém ambos substanciando a análise multicritério, pode-se dizer que a cartografia da fragilidade, mesmo que não sendo dinâmica em seu sentido estrito apresenta resultados aparentemente consistentes quanto à representação de determinadas temáticas, como a fragilidade. 


\section{ANAP $B_{\text {rasil }}$}

\section{Referências Bibliográficas}

ALMEIDA, L.F.B e FILHO, L.M.C. e SILVA, J.X. Geomorfologia e geoprocessamento In: Guerra, A.J.T. e CUNHA, S. B. (org). Geomorfologia: exercícios, técnicas e aplicações. 2ª . Ed. Rio de Janeiro: Bertrand Brasil, 2002, p. 283 - 309.

CARVALHO, W.A. (Coord.). Levantamento semidetalhado dos solos da bacia do rio Santo Anastácio-SP. Presidente Prudente, SP: FCT-UNESP, (Boletim Científico, n.2), 1997.

CASSETTI, V. Ambiente e apropriação do relevo. São Paulo: Contexto, 1991.

COLÂNGELO, A.C. Os mecanismos de compensação e o equilíbrio de forças na dinâmica dos materiais de vertente. In: Revista do Departamento de Geografia, n. 9 FFLCH-USP. p.13 - 20, $1995 b$

CHRISTOFOLETTI, A. Geomorfologia. São Paulo, Edgard Blücher, 2ª e.d., 1980.

FLORENZANO, T.G. (Org).Geomorfologia: conceitos e tecnologias atuais. São Paulo: Oficina de Textos, 2008, 318p.

LEPSCH, I.F. Formação e Conservação dos Solos. 2. Ed. São Paulo: Oficina de Textos, 2010.

Martinelli, M. Cartografia Ambiental: Uma Cartografia Diferente? Revista do Departamento de Geografia, No 7, p.61-80, USP, São Paulo, 1994.

ROSS, J.L.S. Geomorfologia: Ambiente e Planejamento. 9a edição. São Paulo: Editora Contexto. 2012.

ROSS, J.L.S. Ecogeografia do Brasil: Subsídios para o Planejamento ambiental. 1a edição. São Paulo: Oficina de Textos, 2009.

ROSS, J. L. S. Geomorfologia Aplicada aos EIAs - RIMAs In: Guerra, A.J.T. e CUNHA, S. B. (org). Geomorfologia e Meio Ambiente. 4a․ Ed. Rio de Janeiro: Bertrand Brasil, 2002, p. 291 335.

ROSS, J.L.S. Análise empírica dos ambientes naturais e antropizados. Revista do Departamento de Geografia. FFLCH-USP, n.8, p. 63-74, 1994.

ROSS, J.L.S. O registro cartográfico dos fatos geomórficos e a questão da taxonomia do relevo. Revista do Departamento de Geografia. FFLCH-USP, n.6, p. 17-29, 1992.

SANCHEZ, R.O. Zoneamento Agroecológico: Bases para o Ordenamento Ecológico Paisagístico - do Meio Rural e Florestal. Cuiabá, Mato Grosso do Sul: Fundação de Amparo a Pesquisa Cândido Rondon, 1991.

TRICART, J. Ecodinâmica. Rio de Janeiro. IBGE/SUPREN, 1977.

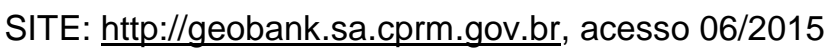

